\title{
La incompleta re-construcción peronista de la frontera: Un análisis desde la región del Nahuel Huapi, Argentina (1946-1955) ${ }^{1}$
}

\section{The peronist incomplete re-construction of border: A study from Nahuel Huapi's region, Argentina (1946-1955)}

\author{
Paula Gabriela Núñez*
}

\section{Resumen}

Este trabajo analiza el efecto económico del peronismo en la región del Nahuel Huapi, revisando aspectos materiales y simbólicos de este sito de frontera con Chile, asociado al Parque Nacional existente en la región y a la ciudad de Bariloche. Con este objetivo, se problematizan el autorreconocimiento y los vínculos con otras regiones, en diálogo con los procesos materiales del periodo. El aporte que presenta este manuscrito es reconocer que, a pesar de que el peronismo es vivido como uno de los grandes quiebres del desarrollo en la región del Nahuel Huapi, y sobre todo en la localidad de San Carlos de Bariloche, los documentos dan cuenta de procesos de continuidad, que discuten el relato rupturista existente.

Palabras clave: peronismo, parques nacionales, turismo, frontera nacional.
Abstract

This paper analyzes the economic impact of Peronism in the Nahuel Huapi region and reviews the material and symbolic aspects of this district, which borders Chile and is associated with both the existing national park in the region and the city of Bariloche. To this end, and in dialogue with the material processes of the period, self-recognition and links to other regions were analyzed. The contribution of this manuscript is its recognition that despite Peronism having been experienced as one of the most significant development shifts in the Nahuel Huapi region, and especially in the town of San Carlos de Bariloche, documents both provide evidence of continuity processes and discuss the existing account of a break.

Keywords: peronism, national parks, tourism, national border.

Recibido: 16 de julio de 2013.

Aceptado: 27 de marzo de 2014.

${ }^{1}$ Este artículo resume parte de los resultados del Proyecto de Investigación Plurianual (PIP) Conicet "La Patagonia Norte en las políticas nacionales de planificación, 19431976”. Código de inscripción 0133.

* Universidad Nacional de Río Negro, Instituto de Investigaciones en Diversidad Cultural y Procesos de Cambio. Dirección: Mitre 630 5to A. R8400, San Carlos de Bariloche, Río Negro, Argentina. Correo electrónico: iidypca@unrn.edu.ar 
Paula Gabriela Núñez / La incompleta re-construcción peronista de la frontera

\section{Introducción}

La historiografía patagónica, desde hace más de 20 años, interpela a la historia nacional argentina, mostrando cómo el proceso nacional se resignifica desde una región de frontera. En los años que nos ocupan, la pertenencia a la frontera se establece en dos sentidos: por una parte, como frontera nacional con Chile; por otra, como frontera del desarrollo (Navarro, 2011). La Patagonia argentina, por su variedad, no puede reducirse a procesos acontecidos en una región específica de la misma. El presente trabajo avanza desde un proceso situado en el oeste norpatagónico, la localidad de San Carlos de Bariloche, puerta de entrada al Parque Nacional Nahuel Huapi, espacio aledaño a Chile (ver figura 1).

Este escrito recorre el efecto simbólico del peronismo histórico, uno de los movimientos políticos más emblemáticos de Argentina, ${ }^{2}$ en la fronteriza región del Nahuel Huapi, a partir de las modificaciones que introdujo el peronismo en las prácticas económicas de la ciudad de Bariloche, y de las respuestas que se generaron en la misma. Para ello, va a caracterizar el modo en que el espacio fue concebido en los años precedentes, en torno a los cuales el peronismo se presenta como una ruptura, pero que, en los bordes de lo construido como naturaleza, se presenta con importantes lógicas de continuidad, que van a trascender el quiebre político que destituyó la presidencia de Perón en 1955.

${ }^{2}$ Se toma como "peronismo histórico" el periodo que comprende las dos primeras presidencias de Juan Domingo Perón en Argentina, esto es, de 1946 a 1955 (Carreras, 2010). En relación con el movimiento político liderado por esta figura, cabe mencionar que a partir de 1943, en Argentina se modifica el reconocimiento social, avanzando en una integración ampliada de sectores obreros. Las elecciones con fraudes explícitos de la década previa, terminaron por minar la legitimidad de gobiernos cuya representación de la ciudadanía estaba cada vez más puesta en duda. El final de un proceso de incertidumbre política fue un golpe de Estado, que en 1943 introdujo a la política nacional la figura del coronel Juan Domingo Perón, a cargo del Ministerio de Trabajo. De allí, y en concordancia con la idea de afianzar la industrialización del país, se ampliaron los derechos laborales y se promovió la participación de sectores urbanos hasta entonces ajenos a la política. Ésta fue la base de consolidación de la fórmula Juan Domingo Perón-Hortensio Quijano, que ganaría las elecciones de 1946, con una fuerte impronta de continuidad con los cambios llevados adelante en el gobierno de facto entre 1943 y 1945, y materializando la política que se conocerá como "justicialismo” o "peronismo". 
Figura 1. Ubicación relativa del Parque Nacional Nahuel Huapi

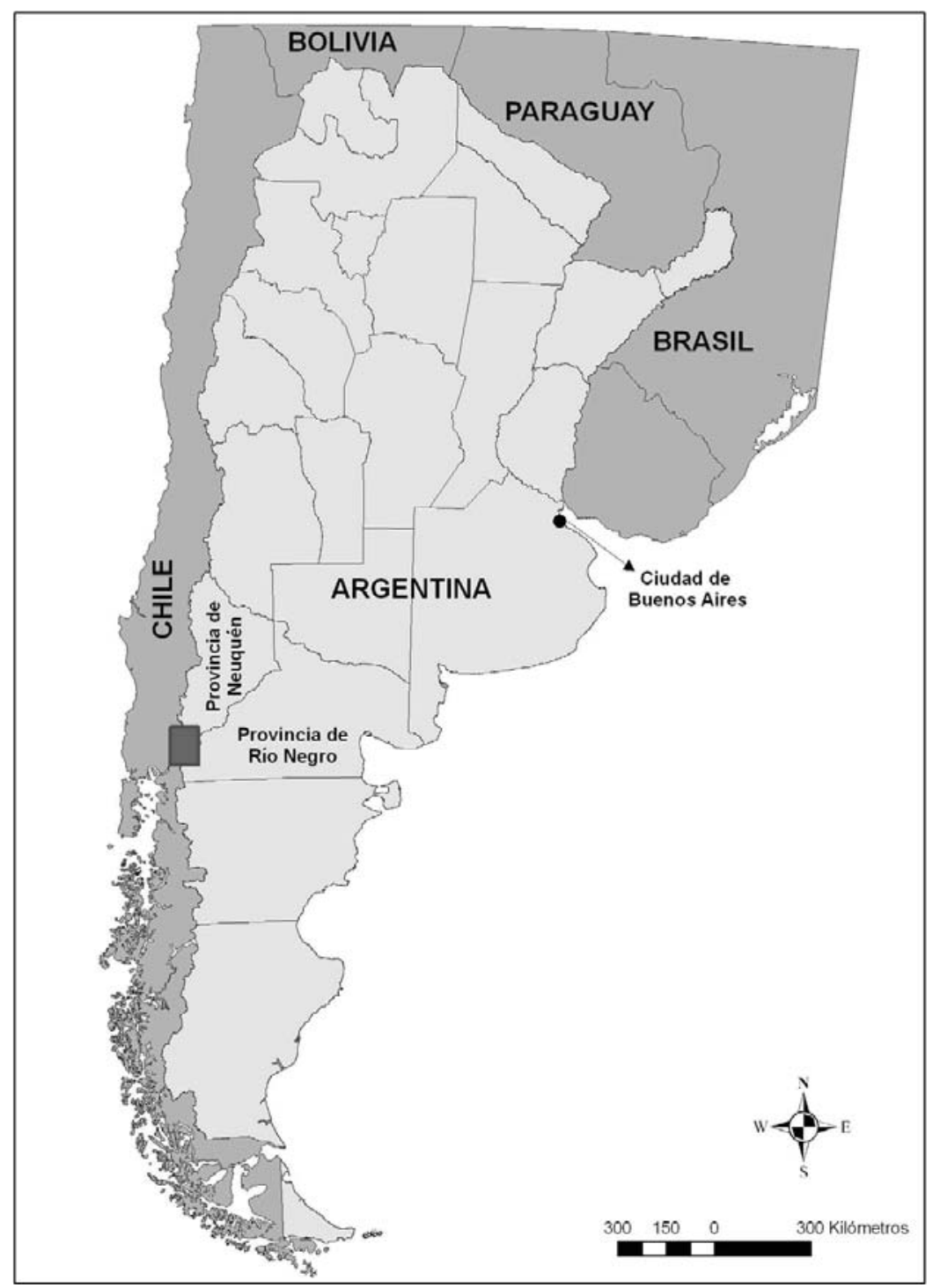

Fuente: Elaborado por B. Matossian sobre las bases gráficas del PIP 5879 Migrantes y territorios urbanos en la Argentina (DIGEO-IMHICIHU-CONICET). 
La noción de turismo, en relación con el aprovechamiento del área natural protegida, resulta clave en la interpretación del peronismo a la luz de los acontecimientos en estos márgenes. Asimismo, la revisión sobre el modo y las consecuencias que tuvo la ampliación de derechos sociales y políticos, que caracterizaron estos años de gobierno, también va a permitir complejizar el proceso nacional.

\section{La re-construcción del Nahuel Huapi}

La región del Nahuel Huapi se presenta como área de interés para el Estado Nacional desde su incorporación a fines del siglo xix. Ya a principios del siglo xx se instala como el espacio de creación de un Parque Nacional, ${ }^{3}$ al tiempo que se abren las fronteras para asegurar el crecimiento económico a partir del comercio binacional (Méndez y Muñoz, 2013). Pero va a ser en la década de 1930 cuando se reconozca el efectivo interés del Estado sobre el espacio. Puesto que es entonces cuando la organización de espacio adopta un carácter centralista, que instala al Estado Nacional como interlocutor excluyente. La institución que edifica la imagen sobre esta región es la Dirección de Parques Nacionales (DPN). En grandes líneas, el proyecto inicial de la DPN buscaba "argentinizar" el área en clave "antichilena", 4 tomando el histórico poblamiento trasandino como una debilidad estructural del desarrollo (Núñez, Matossian y Vejsberj, 2011). Eduardo Bessera (2011) indica que la modernización propuesta para este

${ }^{3}$ En 1903 el perito argentino en el diferendo limítrofe entre Argentina y Chile, F. P. Moreno, dona tres leguas para el establecimiento de un Parque Nacional que resguarde la belleza de la naturaleza de la zona y sirva de espacio de recreación y descanso a las diplomacias del mundo: "en aquella magnificencia tranquila, podrán encontrar sano y adecuado panorama los habitantes de ambos lados de los andes, y contribuir reunidos en comunidad de ideas durante el descanso y solaz cada vez más necesarios en la vida activa del día, a resolver problemas que no llegarán a solucionar nunca los documentos diplomáticos" (Fragmento de la Carta de Donación de Moreno, citado en Sarobe, 1935, p. 262).

${ }^{4}$ La idea de "argentinizar" apela a la proyección del espíritu nacional en territorios de frontera, que son vistos en riesgo por su simple cercanía al país adyacente. Hasta la década de 1920, la región chilena había sido vista, desde el Estado argentino, como la socia estratégica para el desarrollo de la región (Méndez y Muñoz, 2013). 
lugar por la DPN tuvo una impronta conservadora, dirigida y orientada por las elites. El Estado Nacional se constituyó en el artífice del desarrollo local, desconociendo los avances que localmente se habían concretado en la edificación de Bariloche como destino turístico (Navarro y Vejsbjerg, 2009) y fortaleciendo el vínculo hacia el espacio de Buenos Aires, con un desarrollo dependiente y tutelado, omitiendo la previa vinculación con Chile como espacio de posible crecimiento (Navarro, 2007).

La región del Nahuel Huapi se "descubre" en el discurso de la DPN de 1934. El turismo se presenta como su destino manifiesto, planteándose en oposición a las actividades agrícolo-ganaderas y mercantiles desarrolladas en los años anteriores. El devenir económico se materializó en la forma determinada por la institución nacional. San Carlos de Bariloche, como ciudad, se ató a la concepción del Parque Nacional que la circundaba, pues se la concibió como la puerta de entrada de este espacio asumido con un doble carácter, por un lado de naturaleza prístina e intocada (Diegues, 2005), por el otro, sinónimo de argentinidad (Núñez, 2011). Las reflexiones de quien se desempeñó como primer director de la DPN, Exequiel Bustillo, explicitan la vinculación de la constitución de lo nacional y el cuidado de la naturaleza. Así, toma como punto de partida que el bien de la patria debe primar por sobre cualquier otro interés, incluyendo la de la permanencia del paisaje. Señala: "para mantener despierto y alerta el espíritu argentino, para eso y nada más que para eso, Dios ha colocado entre los peligros de la frontera las grandes bellezas de nuestra tierra" (Bustillo, 1946, p. 26). Los Parques, a los ojos de Bustillo, y en línea con la gestión que desarrolla, son explícitamente espacios de formación y consolidación de la ciudadanía. De allí que los espacios de áreas protegidas adquieran una dimensión política estratégica, asociándose, en Argentina, a los cambiantes conceptos de nación (Fortunato, 2005; Diegues, 2005; Carreras, 2010).

Ahora bien, la argentinidad postulada en la década de 1930 tenía un carácter aristocrático, pues el ejercicio de ciudadanía parecía restringido al sector social con influencia en los gobiernos constituidos de la mano de fraudes públicos (Adamovsky, 2009). Esta consideración y valoración sesgada de la ciudadanía se ligó, en la construcción del Parque Nacional Nahuel Huapi, a la valoración de la naturaleza, cuyo reconocimiento fue fundamento para la desestimación de asentamientos poblacionales, 
presentes al momento de establecimiento de la DPN, por motivos raciales, clasistas o xenófobos (Valverde, García y Lara, 2008).

Éste es un punto clave para avanzar sobre las modificaciones que se incorporan durante las dos primeras presidencias de Perón (1946-1952 y 1952-1955). Este gobierno buscó revertir la negación de sectores populares como actores sociales y políticos. Para la Patagonia, un importante antecedente se presenta en el texto de José María Sarobe La Patagonia y sus problemas, obra que gana el concurso de ensayos convocado por el Círculo Militar Argentino en 1934. Este escrito resulta clave para visualizar las tensiones que serán fundamento de las políticas posteriores a la "década infame". ${ }^{5}$ Sarobe fue docente de Juan Domingo Perón en su formación militar y mantuvo contacto y correspondencia durante las décadas de 1930 y 1940 (Barrios, 2008), de modo que resulta un antecedente directo al cambio de sentidos que indaga.

Sarobe formó parte de un sector de oficiales del ejército argentino con inquietudes profesionales e intelectuales — como Enrique Mosconi, gestor de la Fuerza Aérea Argentina y presidente de Yacimientos Petrolíferos Fiscales- que en el periodo de entreguerras asumieron un papel orientador respecto de diversas políticas nacionales (Halperin, 2007), introduciendo un matiz nacionalista, interesado en la revalorización de la defensa - a tono con otros nacionalismos militaristas de la época- y en la búsqueda de la autarquía económica.

El escenario en el que Sarobe presenta su trabajo y gana el concurso del Círculo Militar es de una fuerte división interna del sector militar (Navarro y Núñez, 2012). En ese marco, tanto el discurso de Sarobe como el premio que se le asignó pueden ser interpretados como acciones libradas en un campo disputado acerca del papel del Estado, de la formación territorial del país y de las políticas económicas y sociales. En su obra denuncia el latifundismo, y las dificultades de acceso a la tierra de los pequeños productores, señalando entre los varios ejemplos de manejos criticables, la forma arbitraria en que la DPN estaba permitiendo el acceso a la propiedad privada a un sector privilegiado, que se estaba quedando con lo que debía

${ }^{5}$ Se denomina "década infame" de la República Argentina al periodo que comienza con el golpe de Estado de 1930 y finaliza con el golpe de Estado de 1943. Esta denominación fue utilizada a partir de críticas vinculadas con la legitimidad del fraude en el proceso eleccionario de estos años. 
ser propiedad pública. También denuncia la falta de conexión con Chile, describiendo al Océano Pacífico como "mar del porvenir" y criticando la Punta de Rieles en San Carlos de Bariloche, señalando que la posibilidad de un crecimiento autónomo sólo sería posible con un tren que cruzara la cordillera hacia los puertos chilenos, con una política comercial de fronteras abiertas y un desarrollo industrial basado en la fuerza de los ríos. Otro autor emblemático, Aquiles Ygobone, que ya en 1932 había comenzado a analizar la situación institucional de los territorios tardíamente incorporados a la Argentina, esto es, los Territorios Nacionales, ${ }^{6}$ reitera la permanencia de falencias en textos que, entre 1943 y 1945, vuelven a instalar en los debates la pregunta sobre el desarrollo de la Patagonia, evidenciando en el Estado-nación intereses de carácter errático, que no terminaron de plantearse en un proyecto de crecimiento económico y poblacional sostenido en el territorio.

La gestión peronista repercute profundamente en la DPN y genera la introducción de numerosos cambios vinculados a la nueva perspectiva de integración social. Melina Piglia (2012), en su análisis sobre la Administración General de Parques Nacionales, señala que si bien esta administración puede considerarse el primer ensayo por establecer una política turística sistemática, la constitución de un organismo que centralice todas estas iniciativas va a conformarse en su modo más acabado entre 1945 y 1950, en el marco de la Administración General de Parques Nacionales y Turismo (АGPNyT). Estos cambios se inician en 1943, cuando se modifica la estructura de la DPN transformándose en Dirección de Parques Nacionales y Turismo (DPNyT). Ximena Carreras Doallo (2010) revisa la política general del periodo, observando una re-interpretación de la naturaleza, pues la misma pasa a constituir una de las referencias básicas a los sentidos

${ }^{6}$ Argentina es un país donde se han dado dos lógicas de integración territorial, por un lado están las provincias que forman parte de las primeras definiciones, con representantes en las áreas legislativas desde el principio de la formación estatal, y por otro, los Territorios Nacionales, que ocuparon casi la mitad del espacio nacional y se integran posteriormente y a cuyos habitantes se les restringe el derecho a tener representantes y autoridades elegidos, siendo afectados por un tutelaje del Gobierno Presidencial en su desarrollo. La reflexión sobre esta conformación puede analizarse en los principales referentes sobre el tema, como son el trabajo inaugural de Arias Bucciarrelli (1996) o el texto que recorre el conjunto de la problemática en el país, elaborado por Iuorno y Crespo (2008), entre otros de su misma autoría. 
que se buscaba imprimir en relación con la identidad nacional. ${ }^{7}$ Con la ampliación del reconocimiento social, instalada como base de las políticas públicas, se tensionan las iniciativas precedentes de tal forma que el director histórico de este espacio, Exequiel Bustillo, se aleja de la dirección en 1944.

A partir de 1945, con un nuevo directorio, la dependencia se situó como parte del Ministerio de Obras Públicas, al tiempo que era renombrada como Administración General de Parques Nacionales y Turismo (AgPNyT), dando lugar a una política que buscó vincular la democratización del ocio con la democratización del bienestar nacional (Pastoriza y Torre, 2002). En este contexto, se desarrolla un proceso de resignificación turística de las sierras de Córdoba y el planteo de la democratización del turismo en los Parques Nacionales con una ampliación de la hotelería social, que repercutió en la urbanización del espacio que nos ocupa (Piglia, 2012; Lolich, 2007). A partir de 1951, frente al segundo gobierno de Perón, la administración pública se reorganiza. La re-denominada Administración General de Parques Nacionales (AGPN) vuelve a depender del Ministerio de Agricultura, fortaleciéndose su papel de preservador de espacios naturales. El turismo, como actividad económica, se pierde en las referencias de la institución (Núñez y Vejsbjerg, 2010).

Uno de los puntos clave, en torno a los cuales va a girar la idea de "reconstrucción peronista" de esta región de frontera, es el cambio de una perspectiva de los años treinta, vinculada a lo que Bustillo denominaba "conservacionismo ecléctico". La misma se caracterizaba por una política local subordinada a la nacional, que involucraba el desarrollo urbano y económico de Bariloche, como parte del diseño de preservación. Esta perspectiva se va dejando de lado durante el peronismo, primeramente porque se pierde la atención sobre el desarrollo regional para privilegiar la de la democratización del ocio (Pastoriza y Torre, 2002). En segundo lugar, porque la institución nacional que pesaba en la región, dejó de lado su interés por el turismo para volcarse con más cuidado a la conservación y el

${ }^{7}$ Vale señalar que esta apelación a la construcción identitaria asociada a una cierta interpretación del paisaje no es exclusiva del gobierno de Perón. Las propias fuentes de Bustillo evidencian la intencionalidad política presente en la constitución de las áreas protegidas. Diegues (2005) o Fortunato (2005) son antecedentes de esta línea de reflexión, asociada a la construcción simbólica de los Parques Nacionales en Argentina. 
manejo de los ecosistemas protegidos (Bessera, 2011). Como consecuencia, algunos planes urbanísticos se abandonaron por considerarse opuestos a los intereses de conservación. Éste es un punto de inflexión clave en la relación entre la DPN-DPNyT-AGPNyT-AGPN y la localidad de San Carlos de Bariloche, es decir, entre la nación y la ciudad. La adopción, por parte de la dependencia nacional, de la regencia sobre el desarrollo urbano se desdibuja en el peronismo y ya no vuelve a retomarse. Estas modificaciones no impiden que en 1946, el ya ex director Exequiel Bustillo, dedique un párrafo de reconocimiento a la gestión que lo sucedió, señalando que los Parques Nacionales continúan desarrollándose en su papel fundamental de representar los intereses de la nación (Bustillo, 1946).

\section{Los cambios en el desarrollo}

La DPN se había constituido, no tanto como ámbito de preservación natural, sino como frontera estratégica y desde este esquema se diseñó el desarrollo para la región, negando el valor del intercambio existente hasta 1934. Esta visión se modifica durante el peronismo, cuando el espacio trasandino deja de presentarse como enemigo. Una explicación a esta permutación la acerca Ernesto Bohoslavsky (2006, pp. 495-498), quien marca una diferenciación en el carácter de los nacionalismos en Argentina en las décadas de 1930 y 1940. Este autor indica que las posturas más alineadas a teorías conspirativas, sobre todo en relación con el riesgo de la vulnerabilidad patagónica, se vincularon en la década de 1930 a los nacionalismos "antiobreros, antiizquierdistas y antimodernos", que define como "reaccionarios", "clericalistas" y "defensores de límites a las prácticas democráticas". Sin embargo, y sobre todo a partir de 1932, ciertos nacionalismos comienzan a buscar adhesiones fuera del patriciado, interesándose cada vez más en la problemática social y perdiendo a las teorías conspirativas como referencia. Éstos, se presentan en los orígenes del peronismo.

En este punto resuenan nuevamente los ecos de las palabras de Sarobe como antecedente de las iniciativas tras el golpe de 1943. Para el militar, Chile, lejos de ser un enemigo era el espacio estratégico para el desarrollo patagónico. El problema que sí reconocía el militar era la asimetría fundada en la diferencia demográfica favorable a Chile, uno de los aspectos 
fundamentales que proponía resolver en los territorios del sur. Y el peso de esta perspectiva en los discursos y las prácticas del peronismo se reitera.

Tanto por diferenciarse de las teorías conspirativas más xenófobas, como por acercarse a la articulación estratégica con Chile, o por la intensión de liderar un movimiento latinoamericanista, la gestión de Parques Nacionales durante el gobierno de Perón fue abandonando la idea del "peligro chileno" como fundamento del turismo y de la preservación de la zona. Hay un matiz que debo destacar, como señala Eugenia Scarzanella (2002): el control militar de las áreas lindantes con Chile no se abandonó. Lo que marcamos es que el papel simbólico de Chile, en la región, cobró un lugar diferente y la relevancia de "lo nacional" comenzó a pesar en la integración de los propios grupos subalternos nacionales, antes que en la diferenciación con los países limítrofes.

La valoración de lo indígena se homologa al problema de los trabajadores a partir de la creación de la Comisión Honoraria de Reducciones de Indios, creada en 1943, que refleja el complejo grado de reconocimiento de actores sociales que afectaba a la Patagonia norte en estos años (Lenton, 2010). En 1945 esta comisión es reconocida con capacidades tendientes a resolver el problema indígena, interpretado como problema social, mediante estrategias de integración como la educación o la promoción de la formación agrícola. Ya con la instalación de Juan Domingo Perón en la presidencia, se potencia la búsqueda por consolidar una identidad nacional aglutinadora de estas subalternidades (Delrio, 2005), que sin embargo no pierden la sospecha de extranjería y el riesgo de disidencia (Briones y Lenton, 1997). La desconfianza no se pierde, pero se desdibuja el foco de lo mapuche asimilado a lo chileno y lo chileno asimilado al riesgo inminente. En contraposición a este acontecer norpatagónico, en la Patagonia central y sur el riesgo fue el motor de la intervención estatal del peronismo, reconociéndose, sobre todo, un incremento en la presencia de las fuerzas armadas, que presentan la imagen de un territorio no sólo vulnerable, sino incapaz de decidir por sí mismo (Barros, 2009).

Durante el peronismo, la argentinidad se construyó a partir del ingreso de nuevos actores y no como resguardo de los límites. La ampliación de la pertenencia social se dio a partir de modificar el "ciudadano ideal" reconocido por el Estado, que dejó de ser el propietario ilustrado, para 
constituirse desde los sectores más vulnerables, siendo la figura del "obrero" su referencia más acabada.

Los complejos procesos de ampliación de la ciudadanía en diversos espacios del territorio patagónico han sido largamente revisados (Iuorno y Crespo, 2008; Arias, 1996; Ruffini, 2005; Favaro y Arias, 1995; Masés y Rafart, 2003, entre otros), exhibiendo formas particulares de incorporación ciudadana e incluso de "peronización” en distintos lugares. En general se trató de lograr la mayor adscripción partidaria al movimiento liderado por Juan Domingo Perón, a partir de la creación de unidades básicas y otros espacios de práctica política (Iuorno, 2014). Así, en forma diferenciada, sectores políticos de áreas con problemáticas particulares, se sumaron al histórico reclamo de ampliación de derechos ciudadanos asociados clásicamente a la vinculación con los sectores obreros de las grandes urbes. Darío Macor y César Tcach (2003) reconocen en los procesos regionales, un carácter extra-céntrico, donde el propio peronismo buscó vehículos reivindicativos de las particularidades, con una clara argumentación redistributiva en la relación con la amplia geografía considerada como espacio rural (Girbal, 2008).

Pero el espacio que nos ocupa, el del Parque Nacional Nahuel Huapi y San Carlos de Bariloche, no corresponde a esa compleja diferenciación urbano-rural, ni tampoco contiene elementos reivindicativos claramente enmarcados en algún espacio productivo, o siquiera mayormente afín a la reivindicación por la ampliación de los derechos políticos, que efectivamente se estaba reclamando en otras áreas del propio territorio nacional (Núñez, 2004; Iuorno, 2007). Tal vez por este nivel de particularidad, pueda explicarse que la región del Nahuel Huapi, ubicada en un área de frontera de un Territorio Nacional, fuera "peronizada" de una forma ambigua, donde la incorporación de derechos laborales, como el derecho al ocio, se recuerda como opuesta al desarrollo económico que se estableció con la promoción del "turismo social" (Vallmitjana, 1993).

Debe señalarse que, desde su conformación como Parque Nacional, es discutible que la organización económica pesara en forma determinante, aun en sus inicios. Dado que las referencias en este sentido no se acompañan con una política pública consistente con la retórica (Núñez y Azcoitia, 2011). Así, por ejemplo, la mirada a "lo chileno" como enemigo, constitutivo de la región en la década de 1930, se distanciaba de la política 
internacional de intercambio propuesta durante el gobierno que estaba instalando el Parque Nacional Nahuel Huapi. En los años en que la DPN exacerbaba el antagonismo con Chile, el gobierno nacional avanzaba en acuerdos de intercambios energético y de materias primas (Lacoste, 2003). De esto podemos inferir que, desde los primeros planteos, el desarrollo de la región se ideó diferente al de la nación, o dicho de otro modo, el desarrollo de la región no corrió por los carriles prioritarios del desarrollo nacional.

Así, aun cuando el sentido de la existencia de los Parques Nacionales se modifica durante el peronismo, la falta de anclajes de compromiso respecto del desarrollo local es de larga data. Sin embargo, esta sensación parece agravarse en el periodo peronista, cuando los fundamentos sobre el modo en que se decide sobre la matriz productiva local desconoce la dimensión económica, refiriendo centralmente a los aspectos sociales del turismo (Núñez y Vejsbjerg, 2010). Como se mencionó, durante el peronismo, el turismo pasó a constituirse en un derecho, puesto que el ocio se incorporó como práctica en la vida laboral de los sectores obreros. Las vacaciones pagadas y la reducción de la jornada laboral fueron la base del establecimiento de un tiempo libre que el gobierno se preocupaba por canalizar en estrategias que sirvieran al país.

En el conocimiento de la patria parecía operar la consolidación de la identidad peronista. Los dos objetivos que el Primer Plan Quinquenal define para los Parques Nacionales dan cuenta de los nuevos valores, ya que el sentido de existencia de estos espacios se fundamenta en: 1) salvaguardar las bellezas naturales de la nación, y 2) procurar descanso y esparcimiento de las clases de bajos recursos económicos.

Esta fundamentación es el justificativo del desarrollo de lo que se dio a conocer como "turismo social”, que multiplicó por cinco el número de visitantes que arribaban a Bariloche, pero sin que ello favoreciera de modo importante los intereses directos de los actores económicos locales, que habían crecido en la década precedente (Vallmitjana, 1993). El turismo "de masa", desarrollado por el peronismo, estaba manejado centralmente por los sindicatos y por la Fundación Eva Perón (Scarzanella, 2002), que no tenían en vista los intereses de los históricos visitantes del Parque Nacional Nahuel Huapi, o de los emprendedores locales. La financiación se orientó, en parte, a la finalización de las obras iniciadas en el periodo 
previo, como el cablecarril o la Catedral (Bessera, 2011), y en parte a la edificación de infraestructura para el turismo que se fomentaba, dirigida mayormente a la edificación de hotelería accesible a los presupuestos populares (Lolich, 2000).

Claudia Troncoso y Carla Lois (2004) señalan que la mirada turística del peronismo desconoció sus antecedentes, planteándose como fundacional en sus objetivos y formas de desarrollo. Este desconocimiento puede ayudar a entender cómo el incremento de visitantes fue leído, posteriormente, como un debilitamiento estructural de la localidad y la actividad.

Desde una mirada enfrentada a prácticas elitistas, el peronismo fortaleció el sentido social de las mismas en oposición al sentido económico existente en el imaginario local (Núñez y Azcoitia, 2011). Esto resulta particularmente claro en el Segundo Plan Quinquenal, donde se señala que los destinatarios del turismo son el turismo social, el turismo escolar y el turismo internacional. No hay referencias al turismo de elite, que había sido base del desarrollo previo en Bariloche. Es decir, el desarrollo previo se entendía como ideológicamente contrapuesto a los objetivos del peronismo, pero lejos de plantearse tensión con los antecedentes, simplemente se los ignoró.

En este proceso de cambios hay, sin embargo, una continuidad fundamental. Las decisiones sobre el desarrollo continuaron adoptándose desde Buenos Aires. Las formas paternalistas y tuteladas continuaron operando aun cuando se trabajara en la ampliación de los derechos políticos. El peronismo no subsanó (y de hecho fortaleció) la edificación del territorio nahuelhuapeño como un espacio dependiente de la metrópoli, con límites para pensarse y organizarse a sí mismo, al tiempo que profundizó el alejamiento del turismo como actividad económica relevante de la economía nacional, al reconocer sólo el carácter social de la organización del ocio.

La falta de consideración sobre las particularidades locales se reconoce en una de las actividades de mayor repercusión, que focalizó el espacio sin tomar en cuenta a la ciudad, su historia o su actividad. Se trata de la decisión unilateral del Poder Ejecutivo Nacional de 1951, de desarrollar una planta piloto de energía atómica en la isla Huemul, en el lago Nahuel Huapi, que resultó ser un intento fallido por obtener energía ilimitada a partir de la fusión nuclear. Esta iniciativa, liderada por el científico 
Paula Gabriela Núñez / La incompleta re-construcción peronista de la frontera

austriaco Ronald Richter, acarreó una enorme erogación de gastos (Mariscotti, 1996), que no se articuló con ningún proyecto local.

\section{Estrategias de respuesta al cambio}

Una de las características del gobierno peronista fue la incorporación de sectores sociales subalternos. Este aspecto no resultó ajeno a Bariloche. La sociedad local, atravesada por la lógica jerárquica de la década de 1930, se caracterizaba por desigualdades sociales que afectaron el modo de edificar la ciudad (Núñez, 2007). La inequidad, atravesada en este espacio por la problemática étnica, encuentra nuevas vías de interlocución en el periodo peronista, que redundan, por ejemplo, en el reconocimiento de tierras (Fuentes y Núñez, 2008). La incorporación ciudadana en general implicaba mejoras en los derechos políticos y una preocupación especial por educar a sectores históricamente relegados, en vistas de la nación que se estaba conformando. No debe sorprender, entonces, que los objetivos perdieran de vista la consolidación económica de sectores privilegiados avanzándose, por ejemplo, en el establecimiento de escuelas. En 1947 se instaló en Bariloche el primer colegio secundario, y en 1950 se crea una oficina de inspección de escuelas que permite hacer llegar las necesidades de los establecimientos de la zona salvando muchas trabas burocráticas, al mismo tiempo que se instala una escuela técnica en la localidad (Núñez, 2004). Sin embargo, no hay mayores referencias al acompañamiento en el cambio o complejización de la matriz productiva; por el contrario, las producciones alternativas, como las rurales, se debilitan en la zona aledaña al Nahuel Huapi durante todo el peronismo (Rey, 2005).

La "peronización” del espacio no implicó cambios en la matriz productiva en la localidad. Se trató, más bien, de lograr la mayor adscripción partidaria posible (Iuorno, 2014). En general, la práctica política territoriana reconoce ejercicios de disciplinamiento tempranos, vinculados a fortalecimiento en la centralización de la toma de decisiones (Hudson, 2007), o al control con base en la "máscara del tutelaje" (Ruffini, 2005), prácticas de ordenamiento que existieron en todo el periodo territoriano precedente, y que el peronismo resignificó y reprodujo a la luz de nuevas reivindicaciones sociales. En norpatagonia hay, sin embargo, un elemento que frenó 
la adscripción política. La agenda de las necesidades locales no terminaba de adecuarse a los intereses nacionales, creando por ello una distancia en el ejercicio reivindicatorio que redundó en limitantes en cuanto a la "peronización" del espacio (Arias, 2010). Graciela Iuorno (2007) recorre en las elecciones municipales de otras localidades rionegrinas, el importante grado de adscripción de propuestas partidarias alternativas al justicialismo, al tiempo que el medio de prensa central del área de mayor relevancia económica, el diario Río Negro, repite críticas y reclamos a lo largo de la gestión peronista. ${ }^{8}$

Esta tensión entre la integración de una población históricamente ausente, y del afianzamiento y profundización en la desigualdad de la integración territorial (Navarro, 2011), puede ser explicativa de las llamativas memorias contrapuestas que presentan al peronismo como mejora y debilitamiento, y que se ligan al modo en que la ciudad se inscribe en el Territorio de Río Negro. Los debates políticos de San Carlos de Bariloche, en el periodo, no reconocen como propios los reclamos rionegrinos, desarrollando prácticas políticas que vinculan la localidad andina al Estado nacional, con formas propias, más ligadas a los cambios de la DPN que a lo que acontecía en el resto del espacio de Río Negro. En relación con el proceso peronista, mientras algunos vecinos recuerdan una ampliación de derechos, otros hacen énfasis en las persecuciones, pero el diseño de la práctica turística se percibe como ajeno a la localidad (Núñez, 2007). Una anécdota de color nos situará en las tensiones internas en los que serían los últimos años del peronismo histórico. En 1954, el gobierno municipal, de adscripción justicialista, decide inmortalizar a Eva Duarte y Juan Domingo Perón en dos de sus principales arterias: "Visto que es un deber irrenunciable de la comuna rendir su homenaje al insigne creador del justicialismo General Perón y a la inmortal Jefa Espiritual de la Nación Señora Eva

\footnotetext{
${ }^{8}$ Algunos ejemplos son las notas editoriales del Diario Río Negro: 16 de marzo de 1949, "Urge reparar la ruta 22", sobre las obras que se planifican y no se concretan; 22 de mayo de 1949, "Los municipios de los Territorios", sobre la falta de reconocimiento, a pesar de las leyes; 5 de enero de 1954, "Usos y abusos de la propaganda", sobre los anuncios que no se concretan; 15 de enero de 1954, "Ante una realidad irritante", sobre la situación en los territorios; 23 de julio de 1954, "Corriente eléctrica irregular e insuficiente", sobre la falta de servicios como resultante de la política pública; 3 de septiembre de 1954, “¿Cuántos días por año se trabaja actualmente en las escuelas?", sobre falta de servicios como resultante de la política pública, entre otros.
} 
Perón, procediendo a honrar esta ciudad dándole a dos calles de la misma sus queridos nombres...", ${ }^{9}$ y decide rebautizar calles céntricas.

La celeridad y los términos con que los nombres de estas calles recuperan sus nombres originales después del golpe de Estado de 1955, pone en evidencia las diferencias que se habían estado tejiendo en la sociedad local. Por decreto ${ }^{10}$ se reniega del cambio de nombres a las calles y de las denominaciones al Parque Infantil Municipal, al Estadio Municipal y al Refugio para Peatones en los siguientes términos: "Considerando: que los nombres que actualmente tienen las calles que antes se denominaban Vicealmirante O'Connor y Clemente Onelli, carecen de toda significación ya que están desprovistos de la objetividad que implica el juicio de la historia. Que las denominaciones dadas al Parque Infantil Municipal, al Estadio Municipal y al Refugio Municipal para Peatones son innecesarias y no tienen el valor de los homenajes que puede discernir la posteridad...", se anulan todas las denominaciones del gobierno previo. En los nuevos documentos no se menciona el nombre de Eva o de Perón en ninguna parte de la resolución, buscando modos de redacción estratégicas para borrar de la memoria los acontecimientos de diez años precedentes. No sólo se trata de una modificación de nombres de áreas públicas en un lapso corto, sino de adscripciones partidarias incompletas, o como mencionaba Arias (2010), una agenda local que no termina de encontrar eco en la política nacional.

Lo nacional y lo local se modifican en la fronteriza región del Nahuel Huapi. En las décadas de 1930 y 1940 Bariloche se había constituido como destino turístico. A partir de mediados del siglo xx, esta percepción se repite en las ordenanzas municipales, que en forma reiterada reconocen que la actividad turística constituye la base económica de la localidad, y fundamentan sus acciones de gobierno en torno a esta idea. Las ordenanzas municipales de 1952 comienzan refiriendo a la modificación introducida en 1951, cuando la Administración General de Parques Nacionales (AGPN) pierde su injerencia sobre el turismo, pasando a depender del Ministerio de Agricultura. Frente a estos cambios, los documentos muestran a un

${ }^{9}$ Resolución 38-C-54. Municipalidad de San Carlos de Bariloche. Archivo de Ordenanzas y Resoluciones Municipales. Poder Ejecutivo Municipal.

${ }^{10}$ Decreto 11-955. Municipalidad de San Carlos de Bariloche. Archivo de Ordenanzas y Resoluciones Municipales. Poder Ejecutivo Municipal. 
municipio que se reconoce como responsable de este desarrollo, para lo cual organiza una Comisión de Fomento que se preveía como avance en el crecimiento del turismo. ${ }^{11}$

Esta comisión tenía importantes capacidades, ya que era la encargada de gestionar frente a las autoridades las cuestiones relativas al turismo, promover el progreso edilicio de la ciudad, organizar la propaganda, entre otras iniciativas fundamentales que, hasta la fecha, habían descansado en el organismo nacional. La Comisión de Fomento estaba formada por diversos representantes del municipio y de la sociedad civil, como hoteleros, comerciantes, dirigentes deportivos, periodistas, dado que se pretendía construir un espacio representativo y de consenso. Pero la presidencia descansaba en funcionarios de la DPN-DPNYT-APN.

Sin embargo, este espacio tenía un fuerte talón de Aquiles en su financiamiento. Un punto llamativo es el origen de los fondos que darían la base material para el ejercicio de estas potestades. En principio su actividad se planteó a partir de un impuesto al turista, ${ }^{12}$ cuya implementación tuvo un fuerte carácter de improvisación, dado que el decreto municipal ${ }^{13}$ encarga a los mismos propietarios de hoteles el realizar las retenciones pedidas, sin mayores controles. La organización municipal, durante los años peronistas, priorizó el cuidado de lo cotidiano en detrimento de la planificación económica regional, que fue delegada en la mencionada Comisión de Fomento reconociendo que la falta de datos impedía hacer proyecciones, y dejando en la responsabilidad de los propios hoteleros un desarrollo que quedó subordinado a intereses particulares (Núñez, 2004).

La planificación del turismo era un problema, pero no sólo para el municipio. Desde el esquema de desarrollo nacional el turismo nunca se había presentado como parte del desarrollo estratégico del país, y esto se repitió durante el peronismo. El objetivo fundamental que se reconocía para esta actividad era: " $a$ ) Posibilitar el acceso del Pueblo al conocimiento de las bellezas naturales del país y las creaciones del esfuerzo argentino,

${ }^{11}$ Ordenanza 1-C-52. Municipalidad de San Carlos de Bariloche. Archivo de Ordenanzas y Resoluciones Municipales. Poder Ejecutivo Municipal.

${ }^{12}$ Decreto 1-52. Municipalidad de San Carlos de Bariloche. Archivo de Ordenanzas y Resoluciones Municipales. Poder Ejecutivo Municipal.

${ }^{13}$ Decreto 3-52. Municipalidad de San Carlos de Bariloche. Archivo de Ordenanzas y Resoluciones Municipales. Poder Ejecutivo Municipal. 
aprovechando al mismo tiempo los beneficios del descanso físico y espiritual que proporciona el turismo; $b$ ) Facilitar el acceso del mayor número posible de extranjeros al conocimiento del país, mediante la organización adecuada del turismo hacia los centros de mayor belleza y atracción" (2o Plan Quinquenal, 1952, p. 105), mientras que para actividades reconocidas como económicas - como el desarrollo rural o el minero- entre los objetivos fundamentales se cuenta "procurar la elevación del nivel de vida social, material y cultural de la población” (Presidencia de la Nación Argentina, 1952, p. 111); o "lograr el máximo aprovechamiento de los recursos..." (Presidencia de la Nación Argentina, 1952, p. 153).

El turismo era un derecho social fomentado desde los ministerios de Obras Públicas y Transporte, carácter que incluso permaneció después del golpe de Estado de 1955 que derrocó al gobierno de Juan Domingo Perón y proscribió el partido justicialista. El decreto de Ley 6325, sancionado el 11 de abril de 1956, marca esta continuidad al señalar que "la transferencia de las funciones inherentes al fomento y organización del turismo al Ministerio de Transporte de la Nación, comprende todos los servicios, personal, bienes y créditos afectados a dichas funciones que poseía la ex Administración general de Parques Nacionales y turismo; para la cual la citada dependencia procederá a transferir esos créditos, bienes y personal" (Artículo $3^{\circ}$ ).

En un espacio signado por una enorme dependencia respecto de las decisiones nacionales, donde la autonomía del municipio había sido cercenada desde hacía 20 años, y las opiniones barilochenses continuaron sin tener relevancia en el desarrollo que se proponía para este espacio, la desatención hacia el proyecto local y el repentino alejamiento de la entidad rectora, tuvo como consecuencia el debilitamiento de las formas organizativas locales, dando lugar a planificaciones de rumbo errático y corto plazo, que enfrentaban reiteradamente el pertenecer a una actividad que no terminaba de ser considerada económicamente relevante (Núñez, 2004, 2007).

A este cambio en la organización económica, que se profundiza con el cambio de gobierno, se suma el viraje institucional que en 1955 representó el pasaje de Territorio a Provincia. ${ }^{14}$ La incorporación de San Carlos de

${ }^{14}$ Graciela Iuorno (2007) señala que, tras 65 años sin cambios en la situación políticoinstitucional de los Territorios, la Convención Nacional de 1949 incorporó al pueblo de 
Bariloche al Territorio rionegrino presenta tempranas dificultades. Ya en 1916, vecinos de Bariloche elevan un memorial al entonces presidente de la República, Hipólito Yrigoyen, donde respaldan la necesidad de formar tres nuevas gobernaciones en la Patagonia, entre ellas la Gobernación de los Lagos, con capital en San Carlos de Bariloche. Entre otras menciones, se indica: "No podemos seguir dependiendo, Señor Presidente, sin que se nos siga perjudicando enormemente, de 200 leguas de distancia, a donde debemos recorrer para cualesquiera asunto de importancia, con dos meses de tiempo perdido y los gastos consiguientes..."

Durante los años del peronismo, y en vista a la provincialización que se discute cada vez más desde la segunda presidencia, se recupera como posibilidad esta idea de una provincia separada del antiguo territorio. Esta idea, sin embargo, no termina de consolidarse y San Carlos de Bariloche, ligada fuertemente al gobierno central, se encuentra al final del gobierno peronista como parte de un espacio que no percibe como propio, y con una actividad económica que no se reconoce como tal desde la legislación nacional o provincial, trabando con ello el desarrollo de herramientas legales y financieras como para llevar adelante una política pública que refiera al bien común antes que a intereses particulares. En este proceso el gobierno nacional, tanto en el peronismo de 1943 a 1955, como en la siguiente gestión, evidencia falta de atención a la particularidad de la región. La construcción de marginalidades dentro de la nación podría vincularse con la consolidación de asimetrías de poder en el diseño territorial, que permaneció aun en la cambiante política argentina.

los Territorios Nacionales el mecanismo de elección de presidente y vicepresidente de la nación; el objetivo fue ampliar los derechos políticos, en un orden que muestra que la adscripción al peronismo por parte de la mayoría de la población, fue un elemento que se consideró (Arias, 2010; Ruffini, 2005). El Territorio de Los Andes se había disuelto en 1943, pasando a formar parte de las provincias aledañas de Catamarca, Jujuy y Salta. Los Territorios de Chaco y La Pampa fueron declarados Provincia mediante Ley 14037, del 8 de agosto de 1951. El 10 de diciembre de 1953, la Ley 14-294 dispuso la provincialización del Territorio Nacional de Misiones. El 15 de junio de 1955, por Ley 14-408 Formosa, Neuquén, Río Negro, Chubut y Santa Cruz pasan a ser provincias. Tierra del Fuego permaneció como Territorio Nacional hasta 1992. El 16 de septiembre de 1955, a tres meses de la sanción de la Ley 14-408, un golpe de Estado derroca a Juan Domingo Perón. 
Paula Gabriela Núñez / La incompleta re-construcción peronista de la frontera

\section{Reflexiones finales}

El modo en que se valoró el entorno y la actividad de la localidad relacionada con el Parque Nacional Nahuel Huapi, permite revisar los procesos nacionales desde otra perspectiva, donde el centralismo permanece aun frente a los más profundos cambios políticos. En la escala local, aun cuando el gobierno peronista continuó invirtiendo importantes cantidades de fondos para el desarrollo de la infraestructura turística de la región y el número de visitantes cobró una envergadura sin precedentes, la organización peronista del turismo se presenta perdiendo la referencia hacia el desarrollo local, dado que las mejoras apuntaron a favorecer los derechos sociales antes que a mejorar o consolidar las estructuras económicas de la región. La responsabilidad del desarrollo económico es tomada por un pequeño y débil esquema municipal, que adolece de los fondos necesarios como para imponer un proyecto común en un escenario atravesado por intereses individuales.

El cambio en el papel de la Dirección de Parques Nacionales, o en el sentido que para la nación tuvieron los parques nacionales, perdieron de vista el desarrollo local, cuando esta dependencia cambió de carácter en 1943. En Bariloche, este alejamiento fue percibido en términos de abandono, dado que no había habido lugar para formas de desarrollo independientes en los años previos, y tampoco se diseñaron estrategias de fortalecimiento en la organización local en los años posteriores - la precaria estrategia de financiamiento de la Comisión de Fomento de 1952 ilustra este punto.

Desde su figura de "Territorio Nacional" este espacio continuó atravesado por un desarrollo tutelado desde el gobierno nacional, de modo tal que el ejercicio de autonomía no se recuperó con el abandono del proyecto precedente. El desarrollo local, enmarcado en una lógica subordinada, se modificó desde el gobierno central, repitiendo la unilateralidad de las decisiones y sin construir hacia el nuevo proyecto la legitimidad social que, al menos en un sector de la población, había logrado el proyecto precedente, a pesar de su carácter social excluyente.

Como resultado de este proceso, el carácter de inequidad propio del gobierno conservador, se va a instalar en la memoria local como ideal del desarrollo, prevaleciendo la idea de un quiebre entre el proyecto conservador y el proyecto peronista y dejando abierta, como opciones 
antagónicas, dos formas de planificación ciudadana que no terminan de resolverse.

Aun cuando las rupturas, entre uno y otro proyecto, se desplegaron en el ámbito simbólico antes que en el material, la memoria social ha olvidado los avances del peronismo culpando a este periodo por la pérdida de referencia en el desarrollo, sin problematizar las consecuencias debidas a la edificación de un desarrollo tutelado que cuidó mucho el limitar las iniciativas locales en la década de 1930.

El vínculo con Chile, que podría haber sido la base para un desarrollo binacional de la región turística, quedó reducido al intercambio migratorio, sin mayores iniciativas para establecer iniciativas económicas compartidas (Núñez y Almonacid, 2012). Ésta es una característica que se podría proyectar en la frontera norpatagónica, dado que la planificación del tren binacional que pasaría a unos kilómetros al norte de Bariloche, se propuso sin concretarse durante el peronismo, abandonándose como proyecto en la gestión siguiente. Las críticas de los pobladores de norpatagonia repercutieron en los medios de prensa local, que se hicieron eco del reclamo por la ausencia de políticas de desarrollo regionales. ${ }^{15}$

Podría pensarse que la intensión de "peronizar" tuvo éxito en la zona andina, dados los resultados de las elecciones municipales de esos años, sin embargo, la falta de reconocimiento a los aportes del peronismo, así como a la memoria de los conflictos ideológicos, y la falta de sentido de la pertenencia a Provincia, ponen en evidencia los límites que acarreó la repetición de las tomas de decisión unilaterales, visto como un ataque a la autonomía regional, sin consolidar una alternativa, en línea con el reconocimiento de distancias entre agendas locales y la agenda nacional hecha por Arias (2010).

Este proceso podría leerse como una paradoja, pues al mismo tiempo que los derechos sociales se están ampliando, el reconocimiento de la

\footnotetext{
${ }^{15}$ Editoriales del Diario Río Negro: 20 de enero de 1954: "El ferrocarril a Chile", que marca la promesa incumplida de esta iniciativa; 17 de septiembre de 1954: "Las obras esperadas", que lista los problemas por falta de caminos; 12 de noviembre de 1954: "¿Y el puente sobre el Río Negro?", en un tono similar a la nota precedente; 11 de febrero de 1955: "Los caminos del territorio"; 10 de junio de 1955: "El trasandino del sur", como una promesa a la construcción del tren; y 18 de noviembre de 1955: "Las obras que no se hicieron".
} 
autonomía local, en las áreas alejadas a los espacios centrales, está disminuyendo, todo en un contexto de incremento de los derechos políticos. La falta de linealidad y coherencia en torno a las políticas públicas nos ubica frente a la necesidad de revisar la complejidad que atraviesa la historia del país. En el caso que nos ocupa, podemos pensar que la re-construcción peronista de la región del Nahuel Huapi, lejos de tener un carácter popular en cuanto a la integración regional, reprodujo formas centralistas que incidieron en la posterior falta de legitimación.

\section{Bibliografía}

Adamovsky, E. (2009). Historia de la clase media argentina. Apogeo y decadencia de una ilusión, 1919-2003. Buenos Aires: Planeta.

Archivo de Ordenanzas Municipales (1950-1970). Municipalidad de San Carlos de Bariloche. Consejo Municipal. Poder Ejecutivo y Poder Legislativo Municipal.

Arias, M. (1996). Tendencias en el proceso de conversión de Territorios Nacionales a Provincias. La pervivencia de un horizonte referencial. Revista de Historia UNCO, (6), 131- 153.

Arias, M. (2010). Tensiones en los debates parlamentarios en torno a la provincialización de los Territorios Nacionales durante el primer peronismo. Quinto Sol, (14), 103-124.

Barrios, M. A. (2008). Perón y el peronismo en el sistema-mundo del siglo XxI. Buenos Aires: Biblos.

Barros, S. (2009). Peronismo y politización. Identidades políticas en la emergencia del peronismo en la Patagonia central. Revista Estudios Digital, (22). Recuperado de: < http://www.revistaestudios.unc.edu.ar/articulos02/articulos/barros.php>

Bessera, E. (2011). Exequiel Bustillo y la gestión de los Parques Nacionales. Una aproximación a su concepción de las fronteras como áreas naturales protegidas. En P. Navarro y W. Delrio (Eds.). Cultura y espacio: Contribuciones a la diacronización del corredor Norpatagonia Araucanía (pp. 115-125). Argentina: UNRN.

Bohoslavsky, E. (2006). Los mitos conspirativos y la Patagonia en Argentina y Chile durante la primera mitad del siglo Xx: Orígenes, difusión y supervivencias. Tesis doctoral. España: Universidad Complutense de Madrid. Facultad de Geografía e Historia, Instituto Universitario y de Investigación Ortega y Gasset, Programa de Doctorado América Latina Contemporánea.

Briones, C. y Lenton, D. (1997). Debates parlamentarios y nación. La construcción discursiva de la inclusión/exclusión del indígena. Actas de las Terceras Jornadas 
de Lingüística Aborigen (pp. 303-318). Argentina: Instituto de Lingüística, Facultad de Filosofía y Letras, Universidad de Buenos Aires.

Bustillo, E. (1999). El despertar de Bariloche. Buenos Aires: Sudamericana.

Carreras, X. (2010). La construcción del discurso sobre Nación y Naturaleza en el peronismo histórico (1946-1955). Tesis de maestría inédita. Argentina: Universidad Nacional de Quilmes.

Decreto 1 1-955. Municipalidad de San Carlos de Bariloche. Archivo de Ordenanzas y Resoluciones Municipales. Poder Ejecutivo Municipal.

Decreto 1-52. Municipalidad de San Carlos de Bariloche. Archivo de Ordenanzas y Resoluciones Municipales. Poder Ejecutivo Municipal.

Decreto de Ley 6325. Presidencia de la Nación Argentina. Poder Ejecutivo Nacional. (1956).

Delrio, W. (2005). Mecanismos de tribalización en la patagonia. Desde la gran crisis al primer gobierno peronista. Memoria Americana, (13). 209-242.

Diario Río Negro. (1945-1955). Archivo Río Negro. General Roca.

Diegues, C. A. (2005). El mito moderno de la naturaleza intocada. San Pablo: Center for Research on Human Population and Wetlands.

Favaro, O. y Arias, M. (1995). El lento y contradictorio proceso de inclusión de los habitantes de los Territorios Nacionales a la ciudadanía política: Un clivaje en los años 30. Entrepasados. Revista de Historia, (9), 7-26.

Fortunato, N. (2005). El territorio y sus representaciones como fuente de recursos turísticos. Valores fundacionales del concepto de "Parque Nacional". Revista Estudios y Perspectivas en Turismo, 14(4), 314-348.

Fuentes, D. y Núñez, P. (2008). Robles-Pilar I: Identidad y lucha por la tierra en Bariloche. Argentina: Núcleo Patagónico.

Girbal, N. (2008). El Estado peronista en cuestión. La memoria dispersa del agro argentino (1946-1955). Estudios Interdisciplinarios de América Latina y el Caribe, 19(2), 61-89.

Halperin, T. (2007). Vida y muerte de la República verdadera (1910-1930). Buenos Aires: Emecé.

Hudson, M. (2007). El primer peronismo: Mecanismos de control, centralización y politización del aparato institucional del estado santacruceño. En A. Bona y J. Vilaboa, Las formas de la política en la Patagonia. El primer peronismo en los Territorios Nacionales. Buenos Aires: Biblos.

Iuorno, G. (2007). La provincialización de Río Negro. Interregno y conflicto de intereses nacionales y locales, en M. Ruffini y R. F. Masera (Coords.) Horizontes en perspectiva. Contribuciones para la historia de Río Negro, 1884-1955, (pp. 391405). Viedma: Legislatura de la Provincia de Río Negro.

Iuorno, G. (2014). Mujeres peronistas en la línea sur del Territorio Nacional de Río Negro (1949-1955). Manuscrito presentado para su publicación. 
Paula Gabriela Núñez / La incompleta re-construcción peronista de la frontera

Iuorno, G. y Crespo, E. (Coords.) (2008). Nuevos espacios. Nuevos problemas. Los Territorios Nacionales. Argentina: Universidad Nacional de la Patagonia, Universidad Nacimiento del Comahue, CEHEPYC.

Lacoste, P. (2003). La imagen del otro en las relaciones de la Argentina y Chile (15342000). Buenos Aires: Fondo de Cultura Económica.

Lenton, D. (2010). Los indígenas y el Congreso de la nación Argentina: 18801976. Noticias de Antropología y Arqueología. Recuperado de: <http://www.naya. org.ar/articulos /identi09.htm>

Lolich, L. (2000). La ciudad de Bariloche como banco de pruebas de modelos y modas. Cuadernos de Historia Urbana, 207-228.

Lolich, L. (2007). Arquitectura de los Parques Nacionales, 1934-1955. En R. Gutiérrez (Dir.). Ernesto de Estrada. El arquitecto frente al paisaje (pp. 79-94). Buenos Aires: Cedodal.

Macor, D. y Tcach, C. (Eds.) (2003). La invención del peronismo en el interior del país. Buenos Aires: UnL.

Mariscotti, M. (1996). El secreto atómico de Huemul. Crónica del origen de la energía atómica en la Argentina. Buenos Aires: Sigma.

Masés, E. y Rafart, G. (2003). La patria peronista en la Norpatagonia: Notas sobre el origen del peronismo en Río Negro y Neuquen. En D. Macor y C. Tcach (Eds.), La invención del peronismo en el interior del país (pp. 385-436). Santa Fe: Universidad Nacional del Litoral.

Méndez, L. y Muñoz, S. J. (2013). Alianzas sectoriales en clave regional. La Norpatagonia argentino-chilena entre 1895 y 1920. En M. A. Nicoletti y P. Núñez (Comps.), Araucanía-Norpatagonia: La territorialidad en debate (pp. 152167). Argentina: IIDYPCA.

Navarro, P. (2007). La Comisión del Paralelo 41 (1911-1914). Las condiciones y los límites del "progreso" liberal en los Territorios Nacionales. En F. P. Navarro, Paisajes del Progreso (pp. 235-295). Neuquén: Educo.

Navarro, P. (2011). Territorios marginales: Los desiertos inventados latinoamericanos. Representaciones controvertidas, fragmentadas y resignificadas. En D. Trejo (Coord.), Los desiertos en la historia de América. Una mirada transdisciplinaria (pp. 207-226). México: Universidad Michoacana de San Nicolás de Hidalgo, Universidad Autónoma de Coahuila.

Navarro, P. y Núñez, P. G. (2012). Un territorio posible en la República imposible: El coronel Sarobe y los problemas de la Patagonia argentina. Andes, 23(2). Recuperado de: <http://www.scielo.org.ar/scielo.php?script=sci_ arttext\&pid $=$ S16688 0902012000200006\&lng $=$ es\&nrm =iso $>$

Navarro, P. y Vejsbjerg, L. (2009). El proyecto turístico barilochense antes de Bustillo. Entre la prehistoria del Parque Nacional Nahuel Huapi y el desarrollo local. Estudios y Perspectivas en Turismo, (18), 414-433. 
Núñez, P. (2004). Un municipio alejado, una actividad tangencial y los efectos de un profundo cambio institucional. San Carlos de Bariloche, 1958-1970. Cuadernos del Sur. Revista de Historia, 34, 169-188.

Núñez, P. (2007). Municipio y Provincias. Una indagación en torno a la dinámica relacional a partir de un estudio de caso. Territorios, (16-17), 207-224.

Núñez, P. (2011). Naturaleza ajena en un territorio a integrar: La región del Nahuel Huapi hasta 1955. En P. Navarro y W. Delrio (Eds.), Cultura y espacio: Contribuciones a la diacronización del corredor Norpatagonia-Araucanía (pp. 226140). Argentina: UnRN.

Núñez, P. y Almonacid, F. (2012). Nación y región a mediados del siglo xx. Una mirada comparada sobre la integración de la Norpatagonia en Argentina y Chile. En M. A. Nicoletti y P. Núñez (Eds.), Cultura y Espacio 2. El corredor araucanía Norpatagonia (pp. 168-189). Manuscrito presentado para su publicación.

Núñez, P. y Azcoitia, A. (2011). La normalidad asimétrica de la región de los lagos. Revista de Estudios Avanzados, (15), 55-77.

Núñez, P. y Vejsbjerg, L. (2010). El turismo, entre la actividad económica y el derecho social: El Parque Nacional Nahuel Huapi, 1934-1955. Estudios y Perspectivas en Turismo, 19(6), 930-945.

Núñez, P., Matossian, B. y Vejsbjerg, L. (2011). Frontera impuesta en los confines de la Patagonia: El parque Nacional Nahuel Huapi. Revista Mapping. Centroamérica y el Caribe (1), 55-62.

Pastoriza, E. y Torre, J. C. (2002). La democratización del bienestar. En J. C. Torre (Dir.), Nueva historia argentina, t. vII. Buenos Aires: Sudamericana.

Piglia, M. (2012). En torno a los Parques Nacionales: Primeras experiencias de una política turística nacional centralizada en la Argentina (1934-1950). Revista Pasos, 10(1), 61-73.

Presidencia de la Nación Argentina (1946). 2o Plan Quinquenal 1947-1951. Buenos Aires, Argentina: Secretaría Técnica.

Presidencia de la Nación Argentina (1952). 2ํ Plan Quinquenal. Buenos Aires, Argentina: Subsecretaría de Informaciones.

Resolución 38-C-54. Municipalidad de San Carlos de Bariloche. Archivo de Ordenanzas y Resoluciones Municipales. Poder Ejecutivo Municipal.

Rey, H. (2005). La economía del Nahuel Huapi. En H. Rey, La cordillera Rionegrina. Economía, Estado y sociedad en la primera mitad del siglo xx. Viedma: 2010-Bicentenario.

Ruffini, M. (2005). Peronismo, Territorios Nacionales y ciudadanía política. Algunas reflexiones en torno a la provincialización. Revista Avances del Cesor, (5), 132-148.

Sarobe, J. M. (1935). La Patagonia y sus problemas. Estudio geográfico, económico, político y social de los Territorios Nacionales del sur. Buenos Aires: Aniceto López. 
Paula Gabriela Núñez / La incompleta re-construcción peronista de la frontera

Scarzanella, E. (2002). Las bellezas naturales y la nación: Los Parques Nacionales en Argentina en la primera mitad del siglo xx. Revista Europea de Estudios Latinoamericanos y del Caribe, (73), 5-21.

Troncoso, C. y Lois, C. (2004). Políticas turísticas y peronismo. Los atractivos turísticos promocionados en Visión Argentina (1950). Pasos: Revista de Turismo y Patrimonio Cultural, 2(2), 281-294.

Valltmitjana, R. (1993). 90 años de turismo en Bariloche. Bariloche: Autor.

Valverde, S., García, A. y Lara, B. (2008). Relatos Patagónicos. Historias familiares en la construcción del espacio social en Villa Traful. Buenos Aires: Ferreyra.

Ygobone, A. (1932). Los territorios nacionales y sus condiciones institucionales. Buenos Aires: Autor.

Ygobone, A. (1943). El deber argentino ante la Patagonia. Buenos Aires: Autor.

Ygobone, A. (1945). La Patagonia en la realidad Argentina: Estudio de los problemas sociales, económicos e institucionales de las gobernaciones del sur. Buenos Aires: El Ateneo. 